\title{
Development of New Cultivars via Anther Culture
}

\author{
Richard E. Veilleux \\ Department of Horticulture, Virginia Polytechnic Institute and State University, Blacksburg, VA 24061
}

Since the technique of anther culture was first reported (Guha and Maheshwari, 1966), its promise as a means of generating haploid plants that might be instrumental in developing new cultivars of major crop species has been impatiently awaited. By placing immature anthers containing microspores at the late uninucleate/early binucleate stage of development onto a synthetic medium, development can be modified such that some microspores proceed along an embryogenic, or androgenetic, pathway. By conversion of such embryos into plants, or regeneration of microspore-derived callus, haploid plants can be obtained. Subsequently, the chromosome number of such haploids can be doubled to yield homozygous inbred lines. At first, the technique was limited to only a few species; however, with refinements in tissue culture and selection of responsive genotypes, androgenesis has been observed in a wide array of crops representing diverse taxonomic groups (Bajaj, 1990). Given the length of time generally required to develop new cultivars, we can only now begin to expect release of cultivars that owe their origin to anther culture (Table 1). The citations in this table are not necessarily the first anther culture reports for each crop, but the first reports where haploid green plants were produced. Some species used in early anther culture work are not included in the list because of the difficulties that subsequent researchers encountered when applying the techniques to obtain haploid plants (e.g., tomato).

Using anther culture for plant improvement depends on the breeding system of a crop. For self-pollinated crops, such as wheat (Triticum aestivum L.), rice (Oryza sativa L.), or tomato (Lycopersicon esculentum Mill.), anther culture can be most effectively applied to an $\mathrm{F}_{1}$ hybrid between two breeding lines with complementary characteristics of agricultural significance to fix homozygosity in a single generation, thus avoiding the time required for several generations of inbreeding. Anther-derived doubled haploids could be released directly as cultivars once their field performance has been sufficiently documented. Two possibilities exist for applying anther culture to cross-pollinated crops, depending on whether homozygous lines and hybrid cultivars are already available. If they are available, e.g., maize (Zea mays L.), then anther culture can be used to develop additional inbred lines, as in self-pollinated crops. The difference is that the superior inbred lines developed by anther culture would not be grown directly as cultivars, but would be used to generate hybrid cultivars. For crops where completely homozygous inbred lines are either not already available or difficult to develop, e.g., Brassica or Asparagus, anther culture offers a new means to obtain them. Survival as a haploid provides an immediate and efficient selection against deleterious and lethal genes. Because only a single allele is present at each locus, expression of such deleterious recessive alleles is guaranteed with the result that embryos or plants bearing them will perish through the "monoploid sieve" (Wenzel et al., 1979). Also, derivation of haploids does not depend on male and female fertility, as does inbreeding. Of course, once doubled haploids have been obtained, fertility is generally a prerequisite to their use in further breeding. Finally, for highly heterozygous, clonally propagated crops such as potato (Solanum tuberosum L.), heterogeneity among seedlings derived from heterozygous parents is generally too great for most agronomic characters for releasing and producing hybrid cultivars on a massive scale. Anther culture provides the potential to develop homozygous inbreds for $F_{1}$ hybrid production without sacrificing uniformity, thereby converting propagation from vegetative to hybrid seed.

Work has progressed on all of the above applications of anther culture toward cultivar development. In some instances, a general reduction in vigor has been associated with anther-derived doubled haploids (Baenziger et al., 1989; Marburger and Jauhar, 1989), even

The cost of publishing this paper was defrayed in part by the payment of page charges. Under postal regulations, this paper therefore must be hereby marked advertisement solely to indicate this fact. in comparison with haploids obtained by other means (Powell et al., 1986). Although lowered vigor has not always been the case, it has led to some concern about undesirable gametoclonal variation generated as part of the process. An unexpected elevation of DNA content per cell has been observed among some anther-derived lines (De Paepe et al., 1982; Dhillon et al., 1983), although no general association could be made between agronomic performance and DNA content (Reed and Wernsman, 1989). However, reduction in vigor has not been general and superior anther-derived lines have been reported for several crops (Deaton et al., 1982; de Buyser et al., 1985; Friedt and FouroughiWehr, 1983; Kubba et al., 1989; Schaeffer et al., 1984; Winzeler et al., 1987). The amount of variation obtained, even when the anther donor has been an inbred line, is remarkable. New cultivars that owe their origin to anther culture have been released, mainly in China and France. It is still too soon to determine if these cultivars will have enduring agricultural impact, but some appear promising.

\section{Cultivar development in self-pollinated crops}

Wheat (Triticum aestivum L.). Several cultivars of wheat have been released in China as a direct result of anther culture (Han, 1986). The development of 'Jinghua No. 1' has been most completely described (Daofen, 1986). From the $F_{1}$ of a cross between $F_{1}$ (Lovrin $18 \times 5238-036) \times$ Hongliang No. 4, 400 anthers were cultured. Fortysix anther-derived green plants were obtained, from which 28 selffertile plants were produced after chromosome doubling by colchicine. Seed was increased for these 28 lines, and one line was selected for good performance in field evaluations. After 3 years of regional testing, just 6 years after the initial cross had been made to generate the anther donor, the selected line was released as 'Jinghua No. 1'. More recently, 'Anther Culture 28' has been released in China following a similar protocol, except by selection among the anther-derived plants in the greenhouse for resistance to Erysiphe graminis DC. ex Mérat ; 'Anther Culture 28' demonstrated immunity in the field to the same pathogen (Zhao et al., 1990).

A similar scheme was used by de Buyser et al. (1987) in France for the development of 'Florin', a doubled haploid wheat cultivar. The initial cross was between 'Wizard' and 'Iena', from which 49,266 anthers of the $\mathrm{F}_{1}$ plants were placed into culture. Only 64 green plants were obtained, of which 54 were haploids and 10 spontaneous diploids. Forty-one of the 54 haploids were successfully doubled by colchicine; both these and the 10 spontaneous diploids were increased in the field for two seasons. Eighteen selections were field-tested for 2 years at two locations. Two of these were selected for official tests for registration. Of these, 'Florin', a doubled haploid that resulted from the colchicine treatment, was named, just 7 years after the cross was made to generate the anther donors.

Table 1. Major crop species for which the techniques for derivation of androgenetic haploid plants have been available sufficiently long to begin to expect cultivar releases and the reference in which the derivation of haploid green plants was documented.

\begin{tabular}{ll}
\hline Crop species & \multicolumn{1}{c}{ Reference } \\
\hline Asparagus officinalis & Pelletier et al. (1972) \\
Brassica napus & Wenzel et al. (1977) \\
Brassica oleracea & Kameya and Hinata (1970) \\
Capsicum annuum & Wang et al. (1973) \\
Hordeum vulgare & Clapham (1973) \\
Nicotiana tabacum & Nitsch and Nitsch (1969) \\
Oryza sativa & Niizeki and Oono (1968) \\
Secale cereale & Thomas et al. (1975) \\
Solanum tuberosum & Dunwell and Sunderland (1973) \\
Triticum aestivum & Ouyang et al. (1973); \\
& Picard and de Buyser (1973) \\
Zea mays & 401 Research Group (1975) \\
\hline
\end{tabular}


Rice (Oryza sativa $L$.). Several rice cultivars have been released in China (Table 2) following procedures similar to cultivar development in wheat, i.e., anther culture following hybridization to derive truebreeding, self-pollinated cultivars. The development of 'Hua Han Zhao' (in Chen, 1986) deserves particular attention because two cycles of anther culture were used to combine characteristics from several parents (Fig. 1). Anther culture also has been used to develop inbred rice lines that equal or exceed the vigor and yield of the hybrid cultivars from which they were derived (Zhu and Pan, 1990). Anther-derived rice cultivars are now grown extensively in China.

Tobacco (Nicotiana tabacum L.). Tobacco, a self-pollinating allotetraploid, is the crop for which anther culture techniques can be most efficiently applied. Plantlets emerge directly from anthers in culture, thus eliminating the embryo conversion step. Additionally, the haploid plant frequency is high, haploid plants have a high survival rate on transfer to the greenhouse, and the procedure for chromosome doubling of haploids is simple and efficient. These features have generated a wealth of scientific literature on the performance and features of anther-derived haploids; yet, cultivar release has been disappointing. Three anther-derived tobacco cultivars, 'Tan Yuh 1', 'Tan Yuh 2', and 'Tan Yuh 3', have been released in China (Research Laboratory of Breeding, 1981). However, the North Carolina breeding program recently eliminated their most advanced anther-derived breeding line, NC 744, when it failed a smoke panel evaluation; NC 744 was released as germplasm rather than as a cultivar (Chaplin et al., 1980). The Kentucky and North Carolina breeding programs have released several additional anther-derived germplasm lines of tobacco as sources of pathogen resistance (Nielsen, 1989; Rufty et al., 1990). It remains to be seen if an important North American tobacco cultivar will be released through the application of anther culture.

\section{Cross-pollinated crops}

Maize (Zea mays $L$.). Maize has been the classic example of the power of plant breeding through development of inbred lines followed by subsequent cross pollination between selected inbreds to generate highly heterotic hybrid cultivars. The development of inbred lines has progressed during this century such that double-cross hybridsoriginally required because of the lack of vigor and poor seed set of early inbred lines - are no longer necessary; single crosses between more vigorous inbreds provide most of the maize seed currently used for production (Simmonds, 1979). Using anther culture for rapid development of superior inbreds has been attractive to seed companies

Table 2. Cultivars or germplasm of major crop plants developed by application of anther culture.

\begin{tabular}{lllcl}
\hline \hline \multirow{2}{*}{ Crop } & \multicolumn{1}{c}{ Cultivar } & Country & released & \multicolumn{1}{c}{ Reported by } \\
\hline Asparagus & Andreas & France & 1990 & Corriols et al. (1990) \\
Maize & Huayu 1 & China & 1986 & Wu (1986) \\
Rice & Hua Yu I and II & China & 1976 & Hu and Zeng (1984) \\
& Xin Xiu & China & 1976 & Loo and Xu (1986) \\
& Late Keng 959 & China & 1978 & Loo and Xu (1986) \\
& Tung Hua 1, 2, 3 & China & 1978 & Loo and Xu (1986) \\
& Zhonghua 8 and 9 & China & 1981 & Chen (1986) \\
& Hua Han Zao & China & 1982 & Chen (1986) \\
& Huajian 7902 & China & 1983 & Chen (1986) \\
& Nanhua 5 & China & 1983 & Loo and Xu (1986) \\
& Noll & China & 1983 & Loo and Xu (1986) \\
& Hua 03 & China & 1989 & Yang and Fu (1989) \\
& Guan 18 & China & 1990 & Zhu and Pan (1990) \\
Tobacco & Tan Yuh 1, 2, 3 & China & 1974 & Hu and Zeng (1984) \\
& NC 744y & USA & 1980 & Chaplin et al. (1980) \\
& KDH 926, 959, 960 & USA & 1989 & Nielsen (1989) \\
& NCBMR 42 and 90y & USA & 1990 & Rufty et al. (1990) \\
Wheat & Jinghua 1 & China & 1986 & Daofen (1986) \\
& Florin & France & 1987 & de Buyseret al.(1987) \\
& Anther culture 28 & China & 1990 & Zhao et al. (1990) \\
\hline
\end{tabular}

${ }^{2}$ Many of the original reports are in Chinese and not readily available in most libraries. In these cases, a summary article in English has been cited rather than the original report of release.

${ }^{\mathrm{y}}$ Germplasm lines released rather than cultivars.

\section{'Jianong 485' $\times$ 'Labelit'}

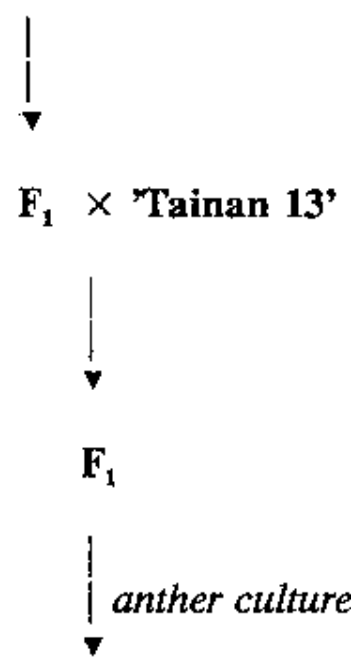

\section{'KeC 1669' $\times$ pollen line 175}

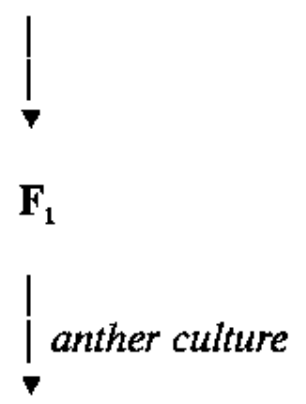

pollen line 76057

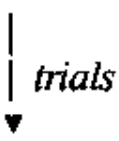

\section{'Hua Han Zhao'}

Fig. 1. Two cycles of anther culture for developing multiparental 'Hua Han Zhao' rice (after Chen, 1986).

for years; however, maize has been more recalcitrant to anther culture than other Gramineae. Chinese researchers have developed a viable anther culture protocol for maize and have been the first to release a cultivar, 'Huayu 1', for which one parent is an anther-derived inbred (Wu, 1986). Several U.S. seed companies are now using anther culture techniques for inbred line development (J.F. Petolino, personal communication).

Asparagus (Asparagus officinalis L.). Anther culture has a unique and recently exploited potential in asparagus breeding, i.e., the development of inbred lines that can be used to generate hybrid, all-male cultivars. Due to dioecy, selfing is generally impossible, except in the occasional andromonoecious cultivars. Sex expression in asparagus may be due to a single gene or gene complex on one chromosome with female and male plants being homomorphic and heteromorphic, respectively, with maleness dominant (Ellison, 1986). Although parthenogenetic haploids have been available in breeding programs for years, they have generally been female plants; anther culture has allowed the development of homozygous supermale plants that can generate all-male progeny when crossed to a female (Doré, 1990). Various parthenogenetic and anther-derived lines have been devel- 
polyenbryonic seed

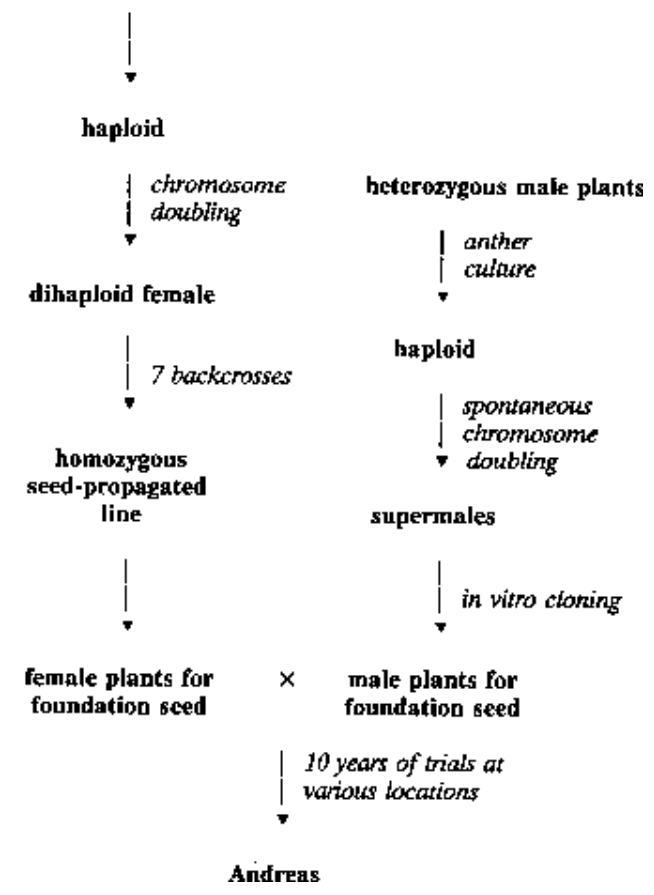

Fig. 2. Breeding scheme for development of 'Andreas', an all-male homogeneous $\mathrm{F}_{1}$ hybrid Asparagus (Corriols et al., 1990).

oped in France, and their hybrids have been evaluated in a breeding program for several years. The first anther-derived, all-male hybrid cultivar, 'Andreas', was recently released (Corriols et al., 1990). The homozygous female parent of 'Andreas' is a parthenogenetic doubled haploid, whereas the homozygous supermale parent is an antherderived doubled haploid (Fig. 2). Yield trials conducted at several locations in different years showed a yield advantage for 'Andreas' compared to leading cultivars (Corriols et al., 1990).

\section{CONCLUSION}

Anther culture is a powerful technique that, within 20 years of its discovery, has begun to have an impact on cultivar release. The short time required to develop completely homozygous lines is the major advantage of anther culture. Most of the anther-derived cultivars to date have been released in China, thus making it difficult to assess their impact. It is also difficult to know how the standards and evaluations for cultivar release in China compare with those in the West, although there are several accounts in which extensive cultivation of antherderived cultivars in China has been reported (Hu and Zeng, 1984; Loo and Yu, 1986; Picard et al., 1990; Zhao et al., 1990). In various breeding programs around the world, androgenetic doubled haploids are being used extensively for cultivar development in eggplant (Solanum melongena L.), pepper (Capsicum annuum L.), barley (Hordeum vulgare L.), and rape (Brassica napus L.). Anther-derived inbred lines of potato that have female fertility have recently been reported (M'Ribu and Veilleux, 1990). A limitation of the technique is that it can be used only on competent germplasm, which depends on the species. As the procedures for anther culture become more routine, and if the technique of anther culture does not become generally associated with the phenomenon of undesirable gametoclonal variation leading to reduction in vigor, we may expect to see its more general application to cultivar development over a wide range of crops.

\section{Literature Cited}

Baenziger, P.S., D.M. Wesenberg, V.M. Smail, W.L. Alexander, and G.W. Schaeffer. 1989. Agronomic performance of wheat doubled-haploid lines derived from cultivars by anther culture. Plant Breeding 103:101-109.

Bajaj, Y.P.S. 1990. In vitro production of haploids and their use in cell genetics and plant breeding, p. 1-44. In: Y.P.S. Bajaj (ed.). Biotechnology in agriculture and forestry 12: Haploids in crop improvement I. SpringerVerlag, Berlin.

Chaplin, J.F., L.G. Burk, G.V. Gooding, and N.T. Powell. 1980. Registration of NC 744 tobacco germplasm. Crop Sci. 20:677.

Chen, Y. 1986. The inheritance of rice pollen plant and its application in crop improvement, p. 118-136. In: H. Hu and H. Yang (eds.). Haploids of higher plants in vitro. Springer-Verlag, Berlin.

Clapham, D. 1973. Haploid Hordeum plants from anthers in vitro. Z. Pflanzenzüchtg. 69:142-155.

Corriols, L., C. Doré, and C. Rameau. 1990. Commercial release in France of Andreas, the first asparagus all-male F1 hybrid! Proc. 7th Intl. Asparagus Symp., 19-23 June 1989, Ferrara, Italy. Acta Hort. 271:249-252.

Daofen, H. 1986. Jinghua No. 1, a winter wheat variety derived from pollen sporophyte, p. 137-148. In: H. Hu and H. Yang (eds.). Haploids of higher plants in vitro. Springer-Verlag, Berlin.

de Buyser, J., Y. Henry, and G. Taleb. 1985. Wheat androgenesis: Cytogenetical analysis and agronomic performance of doubled haploids. Z. Pflanzenzüchtg. 95:23-34.

de Buyser, J., Y. Henry, P. Lonnet, R. Hertzog, and A. Hespel. 1987. 'Florin': A doubled haploid wheat variety developed by the anther culture method. Plant Breeding 98:53-56.

De Paepe, R., D. Prat, and T. Huguet. 1982. Heritable nuclear DNA changes in doubled haploid plants obtained by pollen culture of Nicotiana sylvestris. Plant Sci. Lett. 28:11-28.

Deaton, W.R., P.D. Legg, and G.B. Collins. 1982. A comparison of burley tobacco doubled-haploid lines with their source inbred cultivars. Theor. Applied Genet. 62:69-74.

Dhillon, S.S., E.A. Wernsman, and J.P. Miksche. 1983. Evaluation of nuclear DNA content and heterochromatin changes in anther-derived dihaploids of tobacco (Nicotiana tabacum) cv. Coker 139. Can. J. Genet. Cytol. 25:169-173.

Doré, C. 1990. Asparagus anther culture and field trails of dihaploids and F1 hybrids, p. 322-345. In: Y.P.S. Bajaj (ed.). Biotechnology in agriculture and forestry 12: Haploids in crop improvement I. Springer-Verlag, Berlin.

Dunwell, J.M. and N. Sunderland. 1973. Anther culture of Solanum tuberosum L. Euphytica 22:317-323.

Ellison, J.H. 1986. Asparagus breeding, p. 521-569. In: M.J. Bassett (ed.). Breeding vegetable crops. AVI, Westport, Conn.

Friedt, W. and B. Foroughi-Wehr. 1983. Field performance of androgenetic doubled haploid spring barley from $F_{1}$ hybrids. Z. Pflanzenzüchtg. 90:177-184 .

Guha, S. and S.C. Maheshwari. 1966. Cell division and differentiation of embryos in the pollen grains of Datura in vitro. Nature 212:97-98.

Han, H. 1986. Wheat: Improvement through anther culture, p. 55-72. In: Y.P.S. Bajaj (ed.). Biotechnology in agriculture and forestry 2: Crops I. SpringerVerlag, Berlin.

Hu, H. and J.Z. Zeng. 1984. Development of new varieties via anther culture, p. 65-90. In: P.V. Ammirato, D.A. Evans, W.R. Sharp, and Y. Yamada (eds.). Handbook of plant cell culture. vol. 3. Crop species. Macmillan, New York.

Kameya, T. and K. Hinata. 1970. Induction of haploid plants from pollen grains of Brassica. Jpn. J. Breeding 20:82-87.

Kubba, J., B.M. Smith, D.J. Ockendon, A.P. Setter, C.P. Werner, and M.J. Kearsey. 1989. A comparison of anther culture derived material with single seed descent lines in Brussels sprouts (Brassica oleracea var. gemmifera). Heredity 63:89-95.

Loo, S.-W. and Z.H. Xu. 1986. Rice: Anther culture for rice improvement in China, p. 139-156. In: Y.P.S. Bajaj (ed.). Biotechnology in agriculture and forestry 2: Crops I. Springer-Verlag, Berlin.

Marburger, J.E. and P.P. Jauhar. 1989. Agronomic, isozyme, and cytogenetic characteristics of 'Chris' wheat doubled haploids. Plant Breeding 103:7380.

M'Ribu, H.K. and R.E. Veilleux. 1990. Field evaluation of the breeding value of doubled monoploids from a clone of the diploid potato species, Solanum phureja Juz. \& Buk. Amer. Potato J. 67:566. (Abstr.)

Nielsen, M.T. 1989. Registration of KDH 926, KDH 959, KDH 960 tobacco germplasm lines with different levels of trichome exudate constituents. Crop Sci. 29:1584

Niizeki, H. and K. Oono. 1968. Induction of haploid rice plant from anther culture. Proc. Jpn. Acad. 44:554-557.

Nitsch, J.P. and C. Nitsch. 1969. Haploid plants from pollen grains. Science 163:85-87.

Ouyang, T.W., H. Hu, C.C. Chuang, and C.C. Tseng. 1973. Induction of pollen plants from anthers of Triticum aestivum L. cultured in vitro. Sci. Sinica 16:79-95.

Pelletier, G., C. Raquin, and G. Simon. 1972. La culture in vitro d'anthères d'asperge (Asparagus officinalis). C.R. Acad. Sci. 247:848-851.

Picard, E. and J. de Buyser. 1973. Obtention de plantules haplö̈des de Triticum aestivum L. à partir de culture d' anthères in vitro.C.R. Acad. Sci. 277:14631466.

Picard, E., A. Rode, G. Doussinault, M. Rousset, and M. Rives. 1990. Wheat 
(Triticum aestivum): In vitro production and utilization of doubled haploids, p. 101-124. In: Y.P.S. Bajaj (ed.). Biotechnology in agriculture and forestry. vol. 12: Haploids in crop improvement I. Springer-Verlag, Berlin.

Powell, W., P.D.S. Caligari, and J.M. Dunwell. 1986. Field performance of lines derived from haploid and diploid tissues of Hordeum vulgare. Theor. Applied Genet. 72:458-465.

Reed, S.M. and E.A. Wernsman. 1989. DNA amplification among antherderived doubled haploid lines of tobacco and its relationship to agronomic performance. Crop Sci. 29:1072-1076.

401 Research Group, Laboratory of Plant Cell and Tissue Culture, Institute of Genetics, Academia Sinica. 1975. Primary study on induction of pollen plants of Zea mays. Acta Genet. Sin. 2:143.

Research Laboratory of Breeding. 1981. A preliminary study on the heredity and vitality of the progenies of tobacco pollen plants, p. 223-225. In: H. Hul (ed.). Plant tissue culture. Proc. Symp. Plant Tissue Culture, Peking, 1978. Pitman Publishing, London.

Rufty, R.C., E.A. Wernsman, C.E. Main, and G.V. Gooding, Jr. 1990. Registration of NC-BMR 42 and NC-BMR 90 germplasm lines of tobacco. Crop Sci. 30:241-242.

Schaeffer, G.W., F.T. Sharpe, Jr., and P.B. Cregan. 1984. Variation for improved protein and yield from rice anther culture. Theor. Applied Genet. 67:383-389.

Simmonds, N.W. 1979. Principles of crop improvement. Longman, London.

Thomas, E., F. Hoffman, and G. Wenzel. 1975. Haploid plantlets from microspores of rye. Z. Pflanzenzüchtg. 75:106-113.
Wang, Y., C. Sun, C. Wang, and N. Chien. 1973. The induction of the pollen plantlets of Triticale and Capsicum annuum from anther culture. Sci. Sinica 16:147-151.

Wenzel, G., F. Hoffmann, and E. Thomas. 1977. Anther culture as a breeding tool in rape. I. Ploidy level and phenotype of androgenetic plants. Z. Pflanzenzüchtg. 78:149-155.

Wenzel, G., O. Schieder, T. Przewozny, S.K. Sopory, and G. Melchers. 1979. Comparison of single cell culture derived Solanum tuberosum L. plants and a model for their application in breeding programs. Theor. Applied Genet. 55:49-55.

Winzeler, H., J. Schmid, and P.M. Fried. 1987. Field performance of androgenetic, doubled haploid spring wheat lines in comparison with lines selected by the pedigree system. Plant Breeding 99:41-48.

Wu, J. 1986. Breeding haploid corn by anther culture, p. 149-161. In: H. Hu and H. Yang (eds.). Haploids of higher plants in vitro. Springer-Verlag, Berlin.

Yang, X. and H. Fu. 1989. Hua-03 - A high protein indica rice. Intl. Rice Res. Nwsl. 14(3):14-15.

Zhu, D. and X. Pan. 1990. Rice (Oryza sativa L.): Guan 18-An improved variety through anther culture, p. 204-211. In: Y.P.S. Bajaj (ed.). Biotechnology in agriculture and forestry 2: Haploids in crop improvement I. Springer-Verlag, Berlin.

Zhao, Y., X. He, J. Wang, and W. Liu. 1990. Anther culture 28-A new diseaseresistant and high-yielding variety of winter wheat, p. 353-362. In: Y.P.S. Bajaj (ed.). Biotechnology in agriculture and forestry 13: Wheat. SpringerVerlag, Berlin.

\title{
Observations and Suggestions for Improving Somatic Hybridization by Plant Protoplast Isolation, Fusion, and Culture
}

\author{
Jude W. Grosser ${ }^{1}$ \\ Department of Horticultural Sciences, Citrus Research and Education Center, University of Florida, Institute of \\ Food and Agricultural Sciences, 700 Experiment Station Road, Lake Alfred, FL 33850
}

\begin{abstract}
Methods for the isolation and culture of Citrus protoplasts and subsequent plant regeneration are well developed (Grosser and Chandler, 1987; Grosser and Gmitter, 1990a; Kobayashi et al., 1983; Vardi and Galun, 1988; Vardi et al., 1982). Since the first report of somatic hybrid plant recovery in Citrus (Ohgawara et al., 1985), protoplast fusion techniques have been used to generate somatic hybrid plants from more than 30 parental combinations, including 25 from my laboratory (for reviews, see Gmitter et al., 1992; Grosser, 1991; Grosser and Gmitter 1990a, 1990b), and somatic cybrid plants from five combinations (Vardi et al., 1987, 1989). The comments and suggestions provided herein are based on my observations from research on Citrus, with lesser emphasis on Trifolium, but they may also be applicable to other plant protoplast systems, particularly woody species.
\end{abstract}

\section{Protoplast culture media development}

The complex 8P protoplast culture medium of Kao and Michayluk (1975) has been used for successful protoplast culture and plant regeneration of many plant species. The success of this complex medium is probably due to the appropriate concentrations of the multivitamin, organic acid, and sugar/alcohol additives that are combined with the basal medium formulation. These additives seem to provide additional buffering capacity and reduce the environmental stress on protoplasts by providing required metabolic intermediates.

Florida Agricultural Experiment Station Journal Series no. R-01899. The cost of publishing this paper was defrayed in part by the payment of page charges. Under postal regulations, this paper therefore must be hereby marked advertisement solely to indicate this fact.

${ }^{1}$ Associate Professor, plant cell genetics.
However, optimal basal tissue culture media have been developed for most plant genera, and an efficient protoplast culture medium may be developed for a particular genus by simply supplementing the optimal basal medium with $8 \mathrm{P}$ multivitamin, organic acid, and sugar/alcohol additives. This approach has been successful for Trifolium (Grosser and Collins, 1984; Myers et al., 1989) and Citrus (Grosser, 1991; Grosser and Gmitter, 1990a). Reducing or eliminating the ammonia content of the basal medium may also be useful. Most basal media contain high levels of $\mathrm{NH}_{4} \mathrm{NO}_{3}$ that can often be toxic to protoplasts. Glutamine or $\mathrm{Ca}\left(\mathrm{NO}_{3}\right)_{2}$ have been found to be good alternative sources of $\mathrm{N}$ in protoplast culture media, as demonstrated in BH3 Citrus protoplast medium (Grosser and Gmitter, 1990a) and Populus protoplast media (Russell and McCown, 1986).

Filter-sterilize all protoplast media, enzyme, and fusion solutions. Finally, use fresh protoplast culture media whenever possible, although protoplast culture media can be stored frozen or under refrigeration in brown bottles to prevent photo-oxidation.

\section{Protoplast isolation}

The importance of clean preparations of quality protoplasts cannot be overemphasized, and this starts with appropriate source material. Take leaves for protoplast isolation from vigorous and healthy plants grown under high-humidity and low-light conditions. I recommend using fully expanded, slightly hardened leaves from seedlings or from new flush of older plants. Growth chamber-grown leaves should be free of insecticide residue. When feathering leaves, use a sharp scalpel and avoid cutting near veins in larger, more developed leaves. Vacuum infiltration at 105 to $140 \mathrm{kPa}$ for 15 to $30 \mathrm{~min}$ is useful to increase enzyme penetration; leaves with compact parenchyma tissue may require more time in vacuum. Decontamination should not damage or 